\title{
Effects of incubation temperature on the embryonic viability and hatching time in Russian sturgeon (Acipenser gueldenstaedtii)
}

\author{
Eun Jeong Kim, Chulhong Park ${ }^{2}$ and Yoon Kwon Nam*
}

\begin{abstract}
Background: Russian sturgeon (Acipenser gueldenstaedtii) is an emerging candidate species in the Korean aquaculture domain owing to its highly valued caviar. Although the embryonic development of this species was previously described, the complete image data on the morphological differentiation of developing embryos have not been yet fully available. Further, with the viewpoint of larval production in hatchery, the effects of temperature on embryonic viability and the temporal window of hatching event have not been extensively studied. Hence, the objective of this study was to provide a complete set of photographic image data on the embryogenesis and also to examine the effects of incubation temperatures on embryonic viability and hatching event in farm-bred Russian sturgeon.
\end{abstract}

Results: Typical characteristics of embryonic development including uneven, holoblastic cleavages with unequal blastomeres, followed by the formation of germ layer, neurulation, and organogenesis until hatching, were documented. Under different temperature conditions $\left(12,16\right.$, or $\left.20^{\circ} \mathrm{C}\right)$, viability of embryos incubated at $12{ }^{\circ} \mathrm{C}$ was significantly lower as relative to those of 16 and $20^{\circ} \mathrm{C}$ incubated embryos. Hatchability of embryos was higher, and the timing of hatching event was more synchronized at $20^{\circ} \mathrm{C}$ than at 12 and $16^{\circ} \mathrm{C}$.

Conclusion: Data from this study suggest that the incubation of Russian sturgeon embryos at $20{ }^{\circ} \mathrm{C}$ would be desirable in the hatchery practice with respect to the good hatchability of embryos and the synchronization of hatching events. Additionally, the updated image data for complete embryonic development could be a useful reference guide for not only developmental researches but also artificial propagation of Russian sturgeon in farms.

Keywords: Russian sturgeon, Acipenser gueldenstaedtii, Embryo development, Hatching event, Temperature

\section{Background}

Temperature is one of the most critically recognized environmental factors to influence almost all the physiological aspects of poikilothermal animals, especially embryonic development and early ontogeny (Güralp et al. 2017). Developmental rates of embryos and larvae depend on incubation/rearing temperatures, and the temperature range at which normal development proceeds is species-specific (Güralp et al. 2017; Wang et al. 1985). Knowledge on the optimal temperature range of egg incubation is essential for successful artificial seedling production in aquaculture, and the application of micromanipulation

\footnotetext{
* Correspondence: yoonknam@pknu.ac.kr

'Department of Marine Bio-Materials and Aquaculture, Pukyong National

University, Busan 48513, South Korea

Full list of author information is available at the end of the article
}

and/or chromosome-set manipulation to the embryos often requires the specific temperature regime of egg incubation to make these operations effective (Güralp et al. 2017; Nam et al. 2004; Güralp et al. 2016).

The Russian sturgeon (Acipenser gueldenstaedtii) is an emerging candidate in the Korean aquaculture domain, mainly owing to its highly valued caviar (Ossetra caviar) (Kim et al. 2009). Although the Russian sturgeon was first introduced to Korean farm 15 years ago, reproductive control and artificial seedling production of this sturgeon species have been hardly achieved until the mid-2010s. The pioneering work on the artificial fingerling production with the farmed Russian sturgeon broodfish in a Korean farm was first recorded in 2015 (Park 2018). Developmental stages of Russian sturgeon embryos have been outlined previously by hand-sketched illustrations with 
descriptions on the temperature-dependent development rates (Dettlaff and Vassetzky 1991; Dettlaff et al. 1993). However, with an aquaculture viewpoint on mass production of hatchlings, the embryonic viability incubated at different temperatures has not been extensively studied yet. Furthermore, sturgeons, in particular Russian sturgeon, often represent a considerably wide temporal window of hatching period (i.e., from the first occurrence of advanced hatching to the completion of hatching within a given embryo batch) (Park 2018; Park et al. 2013a). Such a wide window for hatching time occasionally hurdles the synchronization of larval development, consequently making it difficult to decide the best timing to provide first exogenous feed (Gisbert and Williot 1997). Transition to exogenous feeding is a crucial step for successful larval nursery, since this critical phase is immediately followed by a high mortality phase caused by the transient cannibalism (Gisbert and Williot 1997). For this reason, the incubation of artificially produced embryos at optimal temperature at hatchery would be invaluably important for improving the efficiency and capacity of the managing practice for seedling production in this species. We (1) updated the embryonic development of the Russian sturgeon based on the comprehensive photographic data on complete development stages, (2) examined the effects of water temperatures on embryonic viability, and (3) scrutinized the effects of incubation temperature on the temporal window of hatching event.

\section{Methods}

\section{Broodfish, artificial spawning, and insemination}

Mature Russian sturgeon female broodfish $(n=3$; mean body weight $[\mathrm{BW}]=22.6 \pm 4.5 \mathrm{~kg}$ ) were given intramuscular injections of the luteinizing hormone-releasing hormone analogue des-Gly ${ }^{10},\left[\mathrm{D}-\mathrm{Ala}^{6}\right] \mathrm{LH}-\mathrm{RH}$ ethylamide (LHRHa; Syndel Laboratories Ltd., BC, Canada) at the dose level of $20 \mu \mathrm{g} / \mathrm{kg} \mathrm{BW}$. At $12 \mathrm{~h}$ after the primary injection, females were administered again with the LHRHa at the resolving dose of $80 \mu \mathrm{g} / \mathrm{kg} \mathrm{BW}$. On the other hand, male broodfish $(n=4 ; 18.8 \pm 3.9 \mathrm{~kg} \mathrm{BW})$ were injected once with LHRHa $(80 \mu \mathrm{g} / \mathrm{kg} \mathrm{BW})$ at the same time of the second injection for females (Park 2018). After injection, each fish was maintained in individual incubation tanks (3-ton capacity at $16 \pm 1{ }^{\circ} \mathrm{C}$ ). Females were monitored until a small number of ovulated eggs were released (about $36 \mathrm{~h}$ after the second injection), while semen was collected from hormone-injected males with a silicon tube-connected aspirator at $30 \mathrm{~h}$ post injection and stored in an extender at $4{ }^{\circ} \mathrm{C}$ until use (Park and Chapman 2005). Eggs striped from each female and artificial insemination was carried out by gentle mixing eggs with diluted milt (1/100 dilution of extender-suspended milt with $1-\mu \mathrm{m}$ filtered, $16{ }^{\circ} \mathrm{C}$ freshwater) for $2 \mathrm{~min}$. Fertilized eggs were rinsed with clean freshwater and subjected to the treatment of Fuller's earth (Sigma-Aldrich, St. Louis, MO, USA) for removing the adhesiveness of the fertilized eggs (Park 2018). Treated eggs were finally rinsed three times with clean freshwater and placed in the incubation chambers adjusted at desired water temperatures.

\section{Image documentation of embryonic development}

Two independent spawning trials were carried out in different years (2015 and 2017). Documentation of photographic images for embryogenesis was made at 19 $\pm 0.5{ }^{\circ} \mathrm{C}$. Embryos $(n=30-40)$ were sampled with a 1 -h interval until $12 \mathrm{~h}$ post fertilization (HPF), with a 2-h interval until $40 \mathrm{HPF}$, with a 4-h interval until $72 \mathrm{HPF}$, and with a 12-h interval until 120 HPF (first hatch). In addition, several non-periodical samplings of developing embryos were also made when needed. Triplicate samplings were made at each detection point. Sampled embryos were fixed in cold $4 \%$ paraformaldehyde. Outer jelly coats of embryos were removed with fine forceps and subjected to microscopic examination in order to determine the developmental stages and also to scrutinize morphological features of the embryos (Park et al. 2013b). Image analysis was made with the NIS-Elements BR image analysis software implemented in the AZ100 microscope (Nikon, Tokyo, Japan).

\section{Effects of incubation temperature on embryonic viability and hatching}

Effects of incubation temperatures on developmental rates and embryonic viability were examined with egg batches produced in 2015. Fertilized eggs (ca. 800 eggs each) were assigned into one of four incubation chambers at 12,16 , or $20{ }^{\circ} \mathrm{C}$. Water temperatures in incubation chambers were adjusted to be ranged within $\pm 0.5{ }^{\circ} \mathrm{C}$ with thermostat-assisted aquarium $300 \mathrm{~W}$ heaters. Dissolved oxygen was adjusted to be $8.0 \pm 0.5 \mathrm{ppm}$. Dead embryos from each incubation chamber were counted and removed every $12 \mathrm{~h}$. Developmental progress and cumulative survival rate at each temperature group were assessed at early blastula, onset of gastrulation, formation of small yolk plug, late neurulation, s-heart formation, and first hatching. Triplicate analyses were performed.

The time spectra of hatching events under different incubation temperatures $\left(12,16\right.$ and $\left.20^{\circ} \mathrm{C}\right)$ were examined with egg batches produced in 2017. Fertilized eggs were incubated at $17-18{ }^{\circ} \mathrm{C}$ until $100 \mathrm{HPF}$ (stage for tail reaching s-heart), and embryos were divided into three groups $\left(12,16\right.$, and $20{ }^{\circ} \mathrm{C}$ groups). Each temperature group comprised of triplicate batches $(n=500$ per replicate batch). After the allocations, the incubation temperature for each group was adjusted to 12,16 , or $20{ }^{\circ} \mathrm{C}$ with electric thermostat-assisted cooler $(1 \mathrm{~kW})$ or 
heater $(300 \mathrm{~W})$. The temperature decrease/increase rate was $1{ }^{\circ} \mathrm{C} / \mathrm{h}$. Development of embryos in each temperature group was further monitored until the first advanced hatch occurred. Upon the first advanced hatch of a few embryos from each temperature group, pre-hatching embryos $(n=240)$ at tail-beating stage were immediately transferred to each of new incubators (pre-adjusted to 12, 16 , and $20^{\circ} \mathrm{C}$ ) to monitor the temporal pattern of hatching event. Hatched larvae belonging to each temperature group were counted within a 24-h interval. If hatching was no longer recorded in an embryo batch for $48 \mathrm{~h}$, the hatching event of the embryo batch was considered to be complete.

Finally, the optimum temperature regime was validated under a scale-up condition in 2017. Approximately, 70,000 ovulated eggs from two females were inseminated with milt from a single male, and the resultant fertilized eggs were incubated at a selected temperature. Embryonic viability at pre-hatching stage (100 $\mathrm{HPF}$ ) was determined by examining the survival rate with 200 randomly chosen embryo samples (triplicate samplings). On the other hand, temporal pattern of hatching event at the same incubation temperature were examined from $105 \mathrm{HPF}$ (the first advanced hatching detected) by examining 10,000 tail-beating, pre-hatching embryos. Triplicate examinations were carried out.

\section{Statistics}

Differences in embryonic viability and hatchability were assessed with one-way ANOVA followed by Duncan's multiple ranted tests. Differences were considered to be significant when $P<0.05$.

\section{Results and discussion}

Photographic documentation of embryonic development A complete set of photographic images for embryonic development from the fertilization to just before hatching is provided in Additional file 1: Figure S1. Just fertilized embryos (0 HPF) showed an average diameter 3.43 $\pm 0.11 \mathrm{~mm}$ for animal-vegetal axis. Developmental patterns observed in this study were, in overall, accordant with previous descriptions (Dettlaff et al. 1993; Park et al. 2013b), although the onsets and transitions of a particular stage did not exactly match the time points reported in previous works, probably mainly due to the difference in incubation temperatures. Under the present incubation conditions, uneven holoblastic cleavages comprising of irregular blastomeres continued until 10 HPH (Dettlaff et al. 1993). Embryos reached early blastula stage characterized by a primordial cleavage cavity (11 HPF) and the onset of gastrula stage with a typical "dorsal-lip" appearance (18 HPF) (Chebanov and Galich 2011; Bolker 1993). After the process of epiboly cover (22-30 HPF), a slit-like neural groove was formed in the blastopore as a typical sign for the onset of neurulation (34 HPF) (Colombo et al. 2007; Shook and Keller 2008). During neurulation, a pair of rudimentary excretory system appeared as parallel to the central neural groove (Wrobel 2003; Krayushkina et al. 2012), brain rudiment folded, and dorsal-tail region progressively thickened. The neural tube was almost closed at 44 HPF (Lowery and Sive 2004; Vijayraghavan and Davidson 2017). Thereafter, morphogenesis of embryonic body proceeded, with particular highlights on differentiations of heterocercal tail and craniofacial structure. Morphological differentiation of the tail region was characterized by the initial formation of neural groove in blastopore (38 HPF), widened and risen shape (42 HPF), flattened structure with closed neural tube (44 HPF), transformation from flattened shape to rod shape (48 to $56 \mathrm{HPF}$ ), straightened shaping with the development of fin fold rudiments and the separation from the yolk sac (64 to $72 \mathrm{HPF}$ ), pronounced budding of fin fold (84 HPF), bended caudal end with cloaca rudiment (96 to 102 $\mathrm{HPF}$ ), and widened and round-shaped fin fold with a typical cloaca rudiment (108 HPF) (Fig. 1). On the other hand, the differentiation pattern of head and craniofacial region could be characterized by the initial formation of neural plate (36 HPF), formation of rudimentary brain part (38 HPF), distinguishable partition of rudimentary brain (42 HPF), thickened and primarily structured head (44 HPF), from round-shaped to angled head with the development of eyes and olfactory sacs (52 to $64 \mathrm{HPF}$ ) (Zeiske et al. 2003), and highly differentiated structure with brain cavities and auditory vesicle (68 HPF and afterward) (Fig. 2).

Upon hatching (first advance hatching at 105-109 $\mathrm{DPH})$, prolarvae were $10.6 \mathrm{~mm}$ in average total length and the length of yolk (head to tail) was accounted for about $35 \%$ of the total length. In overall, newly hatched Russian prolarvae represented common morphological features typically known in prolarvae of Acipenser species (Dettlaff and Vassetzky 1991; Dettlaff et al. 1993). From the dorsal view, a pair of loop-shaped anterior part of pronephros was distinct and fin fold was developed along the dorsal side of the body. Magnified dorsal view also could allow the identification of faintly pigmented eyes (and eye lens), metencephalon and myelencephalon cavities, auditory vesicles (otocysts), rudimentary base for pectoral fin, and branchial grooves (rudimentary structure for external gills) (Dettlaff and Vassetzky 1991; Dettlaff et al. 1993; Park et al. 2013a). From the lateral view, heterocercal tail with well-developed caudal fin fold was characterized. Blood vessel networks appeared mainly in the posterior/ventral part of the yolk sac wall. Pronephric duct was present along the posterior part of the body trunk until the cloaca. Posterior region of the primary digestive track was filled with dense yolk plug 


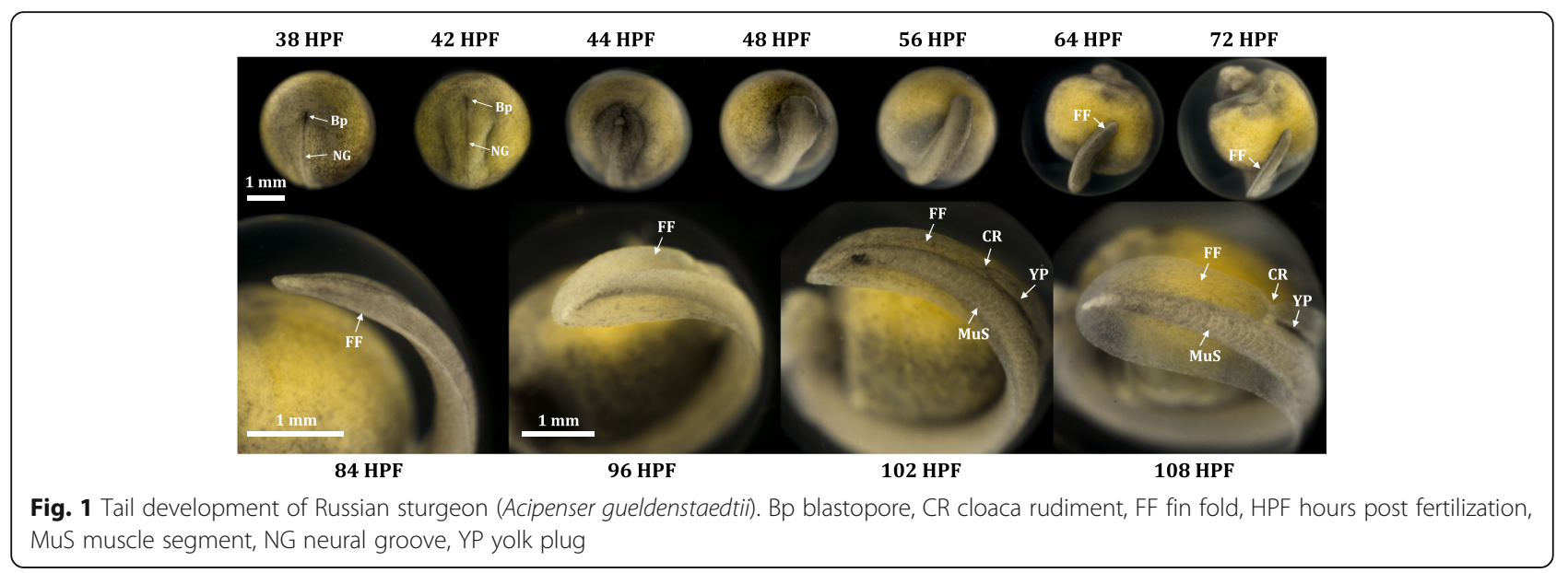

(also called pigment plug), which would be eventually evacuated during the transition from endogenous nutrition to exogenous feeding (Park et al. 2013a; Gisbert and Williot, 1997). Magnified viewing of the head region enabled more detailed documentations of brain cavities and eye structure (optic vesicle and eye lens) (Additional file 2: Figure S2).

\section{Temperature-dependent embryonic viability}

Developmental times required for reaching selected stages were inversely related with the incubation temperatures $\left(12,16\right.$, and $20^{\circ} \mathrm{C}$ ) as expected (data not shown), and the pattern was not significantly different from those observed in previous studies (Chebanov and Galich 2011). However, embryonic viability was affected by the incubation temperature, in which embryos incubated at the lowest temperature $\left(12{ }^{\circ} \mathrm{C}\right)$ was significantly lower than were those of two other temperature groups $\left(16\right.$ and $\left.20^{\circ} \mathrm{C}\right)(P$ $<0.05)$. Significant difference between 12 and $16{ }^{\circ} \mathrm{C} / 20{ }^{\circ} \mathrm{C}$ groups was first detected at onset of gastrulation, and afterward, the difference became progressively intensified until the first hatch (Fig. 3). This finding is well in agreement with previous recommendations on the temperature ranges $\left(14-18{ }^{\circ} \mathrm{C}\right.$ or $\left.16-20{ }^{\circ} \mathrm{C}\right)$ of egg incubation in the Russian sturgeon (Chebanov and Galich 2011). Although reasons for adverse effects at $12{ }^{\circ} \mathrm{C}$ incubation on the embryonic viability has yet to be explained, one possible, but untested, explanation is that activities of enzymes and other modulating effectors responsible for normal development (especially for preparing gastrulation and downstream processes) might be insufficiently presented at the low-incubation temperature. Similar phenomenon has

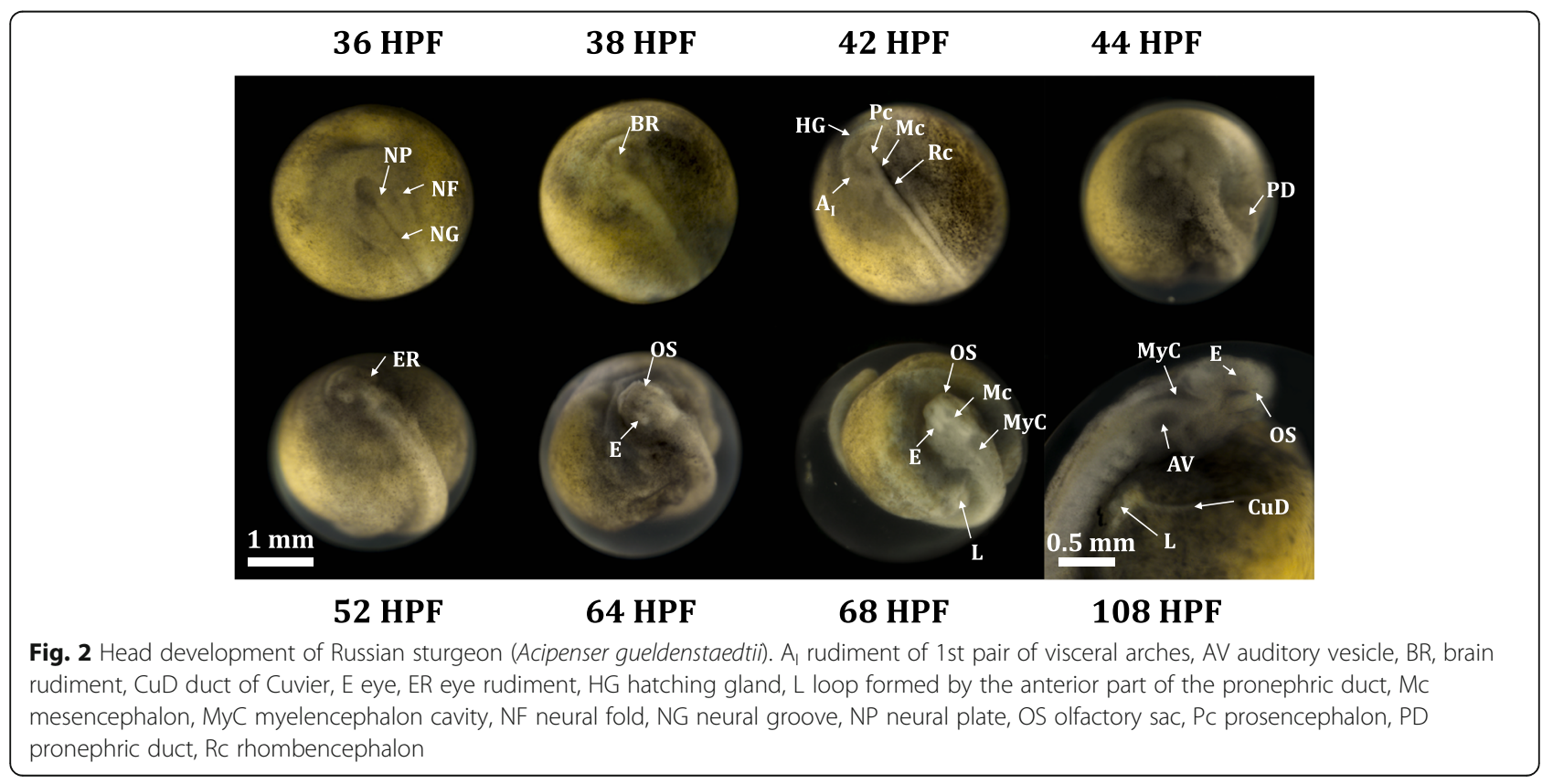




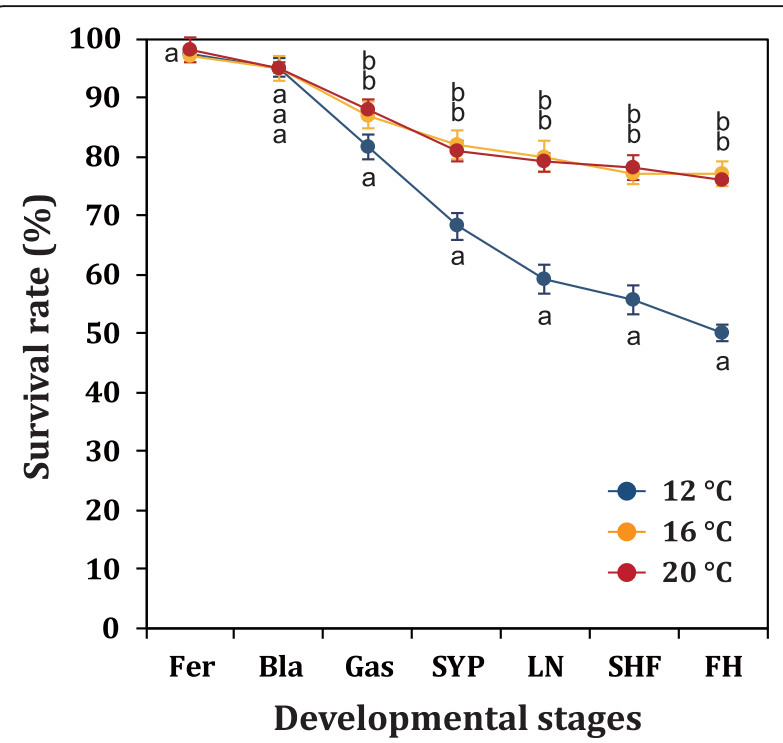

Fig. 3 Survival rates of Russian sturgeon Acipenser gueldenstaedtii embryos incubated at different temperatures $\left(12,16\right.$, or $\left.20^{\circ} \mathrm{C}\right)$.

Abbreviations for selected stages are fertilization (Fer), early blastula (Bla; cleavage cavity identified), onset of gastrulation (Gas; dorsal lip formed), formation of small yolk plug (SYP; $90 \%$ epiboly cover), late neurulation (LN; just closed of neural tube), s-heart formation (SHF; onset of heart beating), and first hatching ( $\mathrm{FH}$; occurrence of the first advanced hatching). Fertilization rate was assessed by the percent embryos showing typical second cleavage furrow at animal hemisphere. Means with different letters indicate significant difference based on ANOVA at $P<0.05$

been reported in the Siberian sturgeon (Park et al, 2013a); however, adverse effects caused by low temperature might be more severe in the Russian sturgeon than in the Siberian sturgeon.

\section{Temporal window of hatching event under different temperature conditions}

Time spectrum of hatching event (i.e., period from the first hatch to the completion of hatching) was also related to the incubation temperature (Fig. 4). When incubated at $12{ }^{\circ} \mathrm{C}$, the hatching event continued even 10 days after the first occurrence of hatching. Although the highest portion of embryos hatched at day- $\mathrm{H} 5$, no apparent peak was evident at $12{ }^{\circ} \mathrm{C}$. Moreover, a considerable portion of embryos (over $40 \%$ for each replicate examination) is persistent to be unhatched with retaining their viability until the end of examination (day-H12) in this study. The overall percent hatching success at Day-H12 (no. of hatched larvae/no. embryos initially incubated at Day-H0 $\times 100$ ) was only $53.7 \pm 4.5 \%$. On the other hand, embryos incubated at $16{ }^{\circ} \mathrm{C}$ showed relatively narrow pattern of the temporal spectrum of hatching event as compared to $12{ }^{\circ} \mathrm{C}$ incubated embryos did. Even though there was still a certain portion of embryos showing delayed hatching (approximately 13\% embryos hatched at day- $\mathrm{H} 7$ and after), the percentage of such embryos were significantly lower than that observed at $12{ }^{\circ} \mathrm{C}$. Over $60 \%$ embryos hatched within a period from day- $\mathrm{H} 3$ to day- $\mathrm{H} 5$, and hatching event was finished at day- $\mathrm{H} 10$ at $16{ }^{\circ} \mathrm{C}$ (overall hatching success $=90.0 \pm 2.6 \%$ ). Further increase of incubation temperature to $20{ }^{\circ} \mathrm{C}$ resulted in the apparently shortened time for finishing the hatching event. At $20{ }^{\circ} \mathrm{C}$, majority of embryos (up to $80 \%$ ) could be successful for hatch-out within 3 days (from day- $\mathrm{H} 2$ to day- $\mathrm{H} 4$ ), and approximately $9 \%$ of embryos hatched the following day (day-H5). However, a few embryos exhibited delayed hatching at day- $\mathrm{H} 6$ and day- $\mathrm{H} 7$. Consequently, the percent hatching success at $20{ }^{\circ} \mathrm{C}$ was $96.7 \pm 2.1 \%$. Overall, our findings are well congruent with previous observations made on Siberian sturgeon embryos treated with similar thermal regimes (Park et al. 2013a). However, when compared to the Siberian sturgeon, the effects of low temperature on the lagged hatching events were more pronounced in the Russian sturgeon embryos. The time windows of hatching event at all the three temperatures tested (particularly at the lowest temperature) were apparently wider in the Russian sturgeon than in the Siberian sturgeon (Park et al. 2013a), suggesting temperature dependency on hatching events might be varied among Acipenser species. More magnified effects of temperature on hatchability and timing spectrum of hatching in Russian sturgeon embryos might be, at least in part, in relation with the fact that outer jelly coat of Russian sturgeon embryo would be stickier and tough compared to that of Siberian sturgeon embryos (personal observations). Although the comparative information on the physicochemical characteristics of the outer jelly coat between the two sturgeon species has remained to be further explored, Russian sturgeon eggs has been reported to require larger amounts and longer treatments of anti-adhesive reagent during the preparation of fertilized eggs than has Siberian sturgeon eggs (Park 2018). Lagged hatching and lowered hatchability at low temperatures might also be potentially associated with either incomplete activity or insufficient amount of hatching enzyme. Hatching enzyme is a protease with a choriolytic activity which can degrade the membrane of egg to let the larvae be free. Hatching enzymes have been isolated and characterized from various teleosts (Kawaguchi et al. 2010; Nagasawa et al. 2016) and also from the Bester sturgeon (hybrid of Acipenser ruthenus and Huso huso) (Nagasawa et al. 2015). However, in contrast to the relative richness of information on in vitro activity of hatching enzyme at different temperature ranges (Shi et al. 2006; Pype et al. 2015), the in vivo expression 

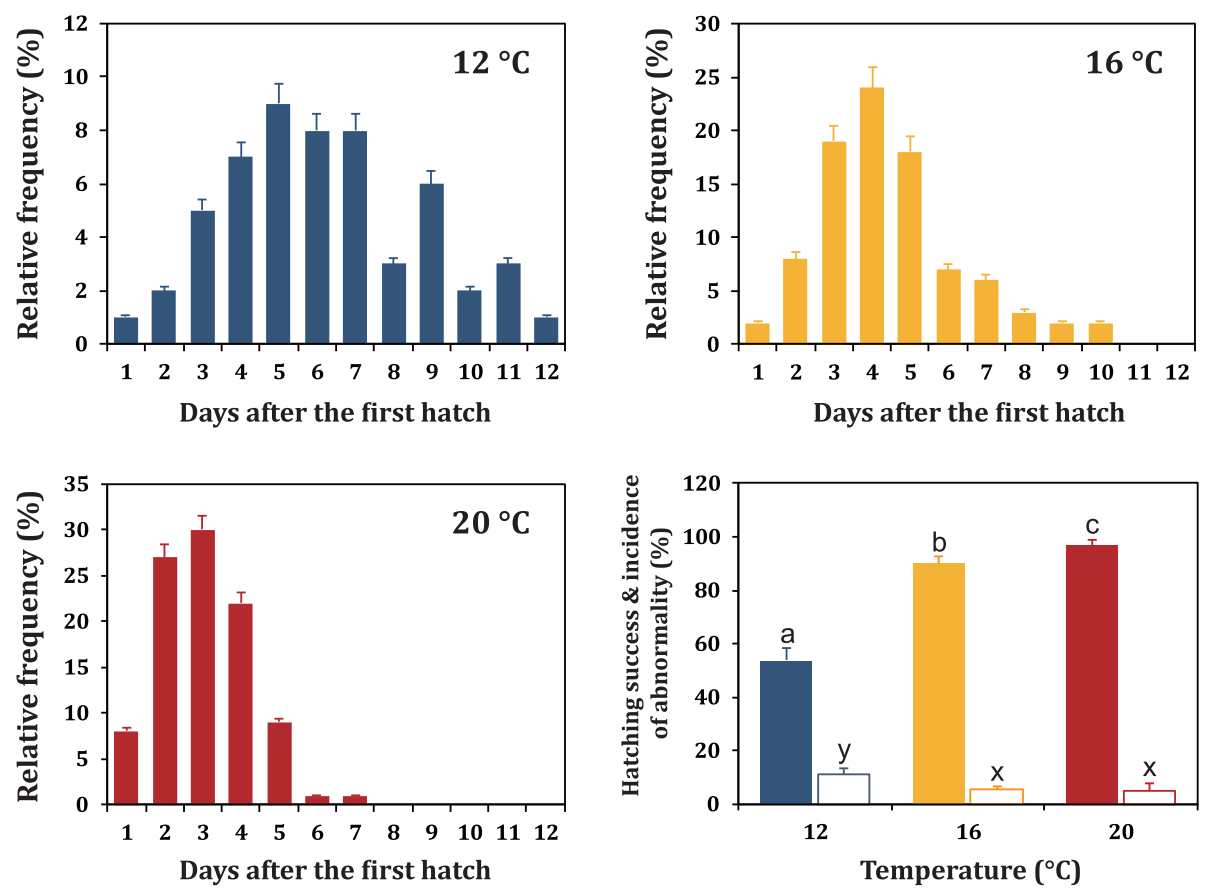

Fig. 4 Effects of incubation temperatures $\left(12,16\right.$, or $\left.20^{\circ} \mathrm{C}\right)$ on the temporal patterns of hatching event in Russian sturgeon Acipenser gueldenstaedtii embryos. Overall percent hatching success (filled boxes) and incidence of abnormal larvae (open boxes) for each temperature group are also provided. Means with different letters (a-c for hatching success and $\mathrm{x}$ and $\mathrm{y}$ for the incidence of abnormality) are significantly different based on ANOVA at $P<0.05$

levels and/or enzyme activity under different water temperature conditions have been little studied. Thereby, expression profiling of hatching enzyme from embryos incubated at different water temperatures could be valuable for future study.

Incidence of abnormality for hatched larvae was also influenced by the incubation temperature. Higher incidence of abnormal larvae was observed at $12{ }^{\circ} \mathrm{C}$ incubated groups $(11.3 \pm 2.3 \%)$ compared to groups incubated at $16^{\circ} \mathrm{C}(5.3 \pm$ $1.5 \%)$ and $20{ }^{\circ} \mathrm{C}(5.0 \pm 2.6 \%)(P<0.05)$. Most of abnormal larvae were characterized by bent shape and incapability of normal swimming (photograph not shown), and such abnormal larvae were more frequently observed from the embryos showing delayed hatching especially at $12{ }^{\circ} \mathrm{C}$. Result from this study (i.e., increased incidence of malformed hatchling at $12{ }^{\circ} \mathrm{C}$ ) is dissimilar from the previous findings from the Siberian sturgeon to have reported no significant difference in abnormality among temperature groups (Park et al. 2013a). Possibly, the difference between these two species might also be related with much more prolonged period of lagged hatching in the Russian sturgeon at $12{ }^{\circ} \mathrm{C}$ as compared to the relatively narrower window of hatching time in the Siberian sturgeon at the same temperature condition (Park et al. 2013a).

Patterns for embryonic development and temporal pattern of hatching event at $20{ }^{\circ} \mathrm{C}$ were confirmed in a large scale. As a result, the percent embryonic viability at $100 \mathrm{HPF}$ was $76.3 \pm 5.6 \%$ based on triplicate examinations. Almost all embryos survived until tail-beating stage could hatch-out (hatchability of tail-beating embryos $=95.5 \pm 2.1 \%$ ), and the temporal pattern for hatching event was clearly similar with that observed in a small scale above. In average, 27, 33, 24, and 7\% embryos hatched at day- $\mathrm{H} 2$, day- $\mathrm{H} 3$, day- $\mathrm{H} 4$, and day- $\mathrm{H} 5$, respectively. Additionally, a small portion of embryos hatched from day-H6 to day- $\mathrm{H} 7$, and eventually a few embryos (3-6\% depending on replicate examinations) remained unhatched. In overall view, the optimal temperature for the incubation of the Russian sturgeon embryos could be $20{ }^{\circ} \mathrm{C}$ regarding the hatchability and/ or normality of larvae. More importantly, synchronized temporal window of hatching events at $20{ }^{\circ} \mathrm{C}$ could offer lots of advantageous merits for hatchery practices. Under hatchery scale, narrowing the window of hatching period would facilitate the preparation of synchronized larval batch, which would eventually be helpful to decide accurately the initial timing for the supply of the artificial (or the live) feeds to yolk plug-evacuated larvae. Transition from yolk sac nutrition to exogenous feeding in sturgeon larvae has been reported to be accompanied with histochemical, enzymatic, and structural changes of the digestive system (Gisbert et al. 1999; Ostos-Carrido et al. 2009; Babaei et al. 2011). During the large-scale production in hatchery, bacterial and fungal infection 
from the dead embryos are often unavoidable; thereby, the completion of hatching events in a short period at $20{ }^{\circ} \mathrm{C}$ would be desirable for reducing the risk associated with the spread of microbial infections.

\section{Conclusions}

A complete set of photographic images for the embryonic development in the Russian sturgeon (Acipenser gueldenstaedtii) was updated, which could be a useful basis not only for developmental studies but also for practical hatchery management of this sturgeon species. Also, our data on effects of water temperature on embryonic viability and hatching times indicate that the egg incubation at $20{ }^{\circ} \mathrm{C}$ are recommended in this sturgeon species with regard to the synchronization of hatching events, which is beneficial for the nursery practice of prolarvae in hatchery.

\section{Additional file}

Additional file 1: Figure S1. Complete images for embryonic development of Russian sturgeon (PDF 11289 kb).

Additional file 2: Figure S2. Morphological characteristics of just hatched Russian sturgeon (Acipenser gueldenstaedtii) prolarva (PDF $375 \mathrm{~kb}$ ).

\section{Abbreviations}

HPF: Hours post fertilization; LHRHa: Luteinizing hormone-releasing hormone analogue

\section{Funding}

This study was supported by the grant from KIMST, Ministry of Oceans and Fisheries of Korea (Grant \#20170327).

\section{Authors' contributions}

EJK carried out the image analysis of embryonic development and experiments including temperature treatments. CHP performed the induced breeding of sturgeon and co-evaluated the data. NYK designed this study, carried out the data evaluation, and drafted the manuscript. All authors read and approved the final manuscript.

\section{Ethics approval and consent to participate}

Experimental protocols followed the guidelines of the Animal Care and Use Committee of Pukyong National University.

\section{Competing interests}

The authors declare that they have no competing interests.

\section{Publisher's Note}

Springer Nature remains neutral with regard to jurisdictional claims in published maps and institutional affiliations.

\section{Author details}

${ }^{1}$ Department of Marine Bio-Materials and Aquaculture, Pukyong National University, Busan 48513, South Korea. ²Dinoville Aquafarm, Hamyang, Kyoung-nam, Gyeongsangnam-do 50027, South Korea.
Received: 13 February 2018 Accepted: 31 May 2018

Published online: 24 September 2018

\section{References}

Babaei SS, Kenari AA, Nazari R, Gisbert E. Developmental changes of digestive enzymes in Persian sturgeon (Acipenser persicus) during larval ontogeny. Aquaculture. 2011;318:138-44.

Bolker JA. The mechanism of gastrulation in the white sturgeon. J Exp Zool. 1993:266:132-45.

Chebanov MS, Galich EV. Sturgeon hatchery manual. FAO Fisheries and Aquaculture Technical Paper. No. 558. Ankara: FAO; 2011.

Colombo RE, Garvey JE, Wills PS. A guide to the embryonic development of the shovelnose sturgeon (Scaphirhynchus platorynchus), reared at a constant temperature. J Appl Ichthyol. 2007;23:402-10.

Dettlaff TA, Ginsburg AS, Schmalhausen OI. Sturgeon fishes: developmental biology and aquaculture. New York: Springer-Verlag; 1993.

Dettlaff TA, Vassetzky SG. Animal species for developmental studies: Vol. 2, Vertebrates. New York: Plenum Publishing; 1991.

Gisbert E, Sarasquete MC, Williot P, Castelló-Orvay F. Histochemistry of the development of the digestive system of Siberian sturgeon during early ontogeny. J Fish Biol. 1999;55:596-616.

Gisbert E, Williot P. Larval behavior and effect of the timing of initial feeding on growth and survival of Siberian sturgeon (Acipenser baerii) larvae under small scale hatchery production. Aquaculture. 1997:156:63-76.

Güralp H, Pocherniaieva K, Blecha M, Policar T, Pšenička M, Saito T. Early embryonic development in pikeperch (Sander lucioperca) related to micromanipulation. Czech J Anim Sci. 2016;61:273-80.

Güralp H, Pocherniaieva K, Blecha M, Policar T, Pšenička M, Saito T. Development, and effect of water temperature on development rate, of pikeperch Sander lucioperca embryos. Theriogenology. 2017;104:94-104.

Kawaguchi M, Hiroi J, Miya M, Nishida M, luchi I, Yasumasu S. Intron-loss evolution of hatching enzyme genes in Teleostei. BMC Evol Biol. 2010;10:e260.

Kim KY, Lee SY, Song HY, Park CH, Nam YK. Complete mitogenome of the Russian sturgeon Acipenser gueldenstaedtii (Acipenseriformes; Acipenseridae). J Fish Sci Technol. 2009;12:35-43.

Krayushkina LS, Gerasimov AA, Kirsanov AA, Mosyagina MV, Ogorzałek A. Structure of pronephros and development of mesonephric kidney in larvae of Russian sturgeon, Acipenser gueldenstaedtii Brandt (Acipenseridae). Zool Pol. 2012;57:5-20.

Lowery LA, Sive H. Strategies of vertebrate neurulation and a re-evaluation of teleost neural tube formation. Mech Dev. 2004;121:1189-97.

Nagasawa T, Kawaguchi M, Sano K, Yasumasu S. Sturgeon hatching enzyme and the mechanism of egg envelope digestion: insight into changes in the mechanism of egg envelope digestion during the evolution of ray-finned fish. J Exp Zool B Mol Dev Evol. 2015;324:720-32.

Nagasawa T, Kawaguchi M, Yano T, Sano M, Okabe M, Yasumasu S. Evolutionary changes in the developmental origin of hatching gland cells in basal rayfinned fishes. Zool Sci. 2016:33:272-81.

Nam YK, Choi GC, Kim DS. An efficient method for blocking the 1st mitotic cleavage of fish zygote using combined thermal treatment, exemplified by mud loach (Misgurnus mizolepis). Theriogenology. 2004;61:933-45.

Ostos-Carrido MV, Llorente Jl, Camacho S, García-Gallergo M, Sanz A, Domezain Z, Carmona R. Histological, histochemical and ultrastructural changes in the digestive tract of sturgeon Acipenser naccarii during early ontogeny. In: Carmona R, Domezain A, García-Gallego M, Hernando JA, Rodríguez F, RuizRejón $\mathrm{M}$, editors. Biology, conservation and sustainable development of sturgeons. Dordrecht: Springer; 2009. p. 121-36.

Park $\mathrm{CH}$. Artificial seedling propagation and caviar production in farmed Siberian sturgeon (Acipenser baerii) and Russian sturgeon (A. gueldenstaedtii). PhD. Thesis. Busan: Pukyong National University; 2018.

Park $\mathrm{CH}$, Chapman FA. An extender solution for the short-term storage of sturgeon semen. N Am J Aquac. 2005;67:52-7.

Park CH, Lee SY, Kim DS, Nam YK. Effects of incubation temperature on egg development, hatching and pigment plug evacuation in farmed Siberian sturgeon Acipenser baerii. Fish Aquat Sci. 2013a;16:25-34.

Park CH, Lee SY, Kim DS, Nam YK. Embryonic development of Siberian sturgeon Acipenser baerii under hatchery conditions: an image guide with embryological descriptions. Fish Aquat Sci. 2013b;16:15-23.

Pype C, Verbueken E, Saad MA, Casteleyn CR, Van Ginneken CJ, Knapen D, Van Cruchten SJ. Incubation at $32.5{ }^{\circ} \mathrm{C}$ and above causes malformations in the zebrafish embryo. Reprod Toxicol. 2015;56:56-63. 
Shi ZP, Fan TJ, Cong RS, Wang XF, Sun WJ, Yang LL. Purification and characterization of hatching enzyme from flounder Paralichthys olivaceus. Fish Physiol Biochem. 2006;32:35-42.

Shook DR, Keller R. Epithelial type, ingression, blastopore architecture and the evolution of chordate mesoderm morphogenesis. J Exp Zool B Mol Dev Evol. 2008:310:85-110

Vijayraghavan DS, Davidson LA. Mechanics of neurulation: from classical to current perspectives on the physical mechanics that shape, fold, and form the neural tube. Birth Defects Res. 2017;109:153-68.

Wang YL, Binkowski FP, Doroshov SI. Effect of temperature on early development of white and lake sturgeon, Acipenser transmontanus and A. fulvescens. Environ Biol Fish. 1985;14:43-50.

Wrobel KH. The genus Acipenser as a model for vertebrate urogenital development: the müllerian duct. Anat Embryol. 2003;206:255-71.

Zeiske E, Kasumyan A, Bartsch P. Hansen A. Early development of the olfactory organ in sturgeons of the genus Acipenser: a comparative and electron microscopic study. Anat Embryol. 2003:206:357-72.

Ready to submit your research? Choose BMC and benefit from:

- fast, convenient online submission

- thorough peer review by experienced researchers in your field

- rapid publication on acceptance

- support for research data, including large and complex data types

- gold Open Access which fosters wider collaboration and increased citations

- maximum visibility for your research: over $100 \mathrm{M}$ website views per year 